\title{
Universidade do Povo (1946-1957) educação de adultos e democratização da sociedade no projeto político-pedagógico de Paschoal Lemme
}

Cristiane Fernanda Xavier'

RESUMO

Este artigo analisa o sentido e as motivações pelas quais Paschoal Lemme (1904-1997) relevou o papel da educação de adultos no processo de democratização da sociedade, evidenciando a reverberação das suas ideias na Universidade do Povo (UP). A partir do entrecruzamento de fontes - relatório, cartilhas e jornais de época, as Memórias de Lemme e parte da sua produção intelectual - , considero que o projeto de sociedade idealizado por Lemme inovou ao associar educação de adultos, participação política e melhoria das condições econômicas dos trabalhadores e que o modelo educativo da UP foi aquele que melhor traduziu as aspirações do Educador.

PALAVRAS-CHAVE

Paschoal Lemme; Universidade do Povo; educação de adultos.

'Universidade Federal de Alfenas, Alfenas, MG, Brasil. 
UNIVERSITY OF THE PEOPLE (1946-1957)

ADULT EDUCATION AND DEMOCRATIZATION OF SOCIETY IN PASCHOAL LEMME'S POLITICAL EDUCATIONAL PROJECT

\begin{abstract}
This paper analyzes the meaning and motivations for which Paschoal Lemme (1904-1997) highlighted the role of adult education in society's democratization process, evidencing the reverberation of his ideas at University of the People (UP). From the intertwining of sources - report, booklets and newspapers from that time, the Memories of Lemme and part of his intellectual production - I consider that Lemme's project of society innovated by associating adult education, political participation and improvement of worker's economic conditions, and that UP's educational model was the one that best translated the aspirations of the Educator.
\end{abstract}

KEYWORDS

Paschoal Lemme; University of the People; adult education.

UNIVERSIDAD DEL PUEBLO (1946-1957)

EDUCACIÓN DE ADULTOS Y DEMOCRATIZACIÓN DE LA SOCIEDAD EN PROYECTO POLITICO-PEDAGÓGICO DE PASCHOAL LEMME

\title{
RESUMEN
}

En este artículo se analiza el significado y las motivaciones de Paschoal Lemme (1904-1997) para poner de relieve el papel de la educación de adultos en el proceso de democratización de la sociedad haciendo hincapié la reverberación de sus ideas en la Universidad del Pueblo (UP). A partir de entrecruzamiento de las fuentes - reporte, folletos y periódicos de tiempos pasados, los recuerdos Lemme y parte de su producción intelectual - creo que el proyecto de la sociedad diseñada por Lemme fue innovador en la vinculación de la educación de adultos, la participación política y la mejora de las condiciones económicas de los trabajadores y que el modelo educativo de la UP era la mejor traducción de las aspiraciones de Educador.

PALABRAS CLAVE

Paschoal Lemme; Universidad del Pueblo; educación de adultos. 


\section{INTRODUÇÃO}

Particularmente nas décadas de 1930 e 1940, movimentos de esquerda e o governo brasileiro disputaram a organização do operariado com o propósito de conferir legitimidade à figura do trabalhador como ator social e político. $\mathrm{O}$ sindicalismo assumiu destacada relevância e a associação entre participação política e instrução foi acentuada.

Nesse contexto, em fevereiro de 1946, o Movimento Unificador dos Trabalhadores (MUT) — organização ligada ao Partido Comunista do Brasil (PCB) — criou a Universidade do Povo (UP), na cidade do Rio de Janeiro. Destinada à educação de adultos, a UP proporcionava ensino gratuito em "cursos de continuação e aperfeiçoamento" dos mais variados, "cursos de extensão cultural", bem como desenvolveu uma campanha de alfabetização apoiada em material didático próprio.

Estreitamente envolvido com os comunistas, Paschoal Lemme, educador dedicado à luta pela educação dos trabalhadores desde os anos de 1930, foi ativo colaborador da Instituição desde a sua fundação. ${ }^{1}$ Com base nessas relações, o presente artigo objetivou analisar o sentido e as motivações pelas quais Lemme relevou o papel da educação de adultos no processo de democratização da sociedade, evidenciando a reverberação das suas ideias e defesas na criação e atuação da UP.

Para tanto, contextualizo a emergência da UP a partir das relações entre Estado e movimento operário. Situo a posição da educação de adultos na conformação do pensamento social de Lemme e focalizo as ressonâncias das suas proposições na experiência da UP, especialmente no que se refere ao problema do analfabetismo e à necessidade de habilitar os trabalhadores para a participação política.

\section{ESTADO E MOVIMENTO OPERÁRIO - ANTECEDENTES}

Historicamente, o movimento operário brasileiro foi um espaço de atuação de diferentes organizações com o propósito de conferir legitimidade à figura do trabalhador como um ator social e político. Se durante a Primeira República os trabalhadores eram vistos com desconfiança e preocupação pelo governo, tidos como ameaça à estabilidade e à segurança, no pós-1930 o próprio Governo passou a disputar com os movimentos de esquerda a organização do operariado. Nesse contexto, o sindicalismo assumiu destacada relevância, acentuando a associação entre participação política e instrução.

No que diz respeito às organizações que atuaram no movimento operário, Ângela de Castro Gomes (2005) aponta que, particularmente no Rio de Janeiro, a presença dos socialistas foi sustentada pela intenção de emancipar os trabalhadores por meio da organização de um partido no qual o operariado deveria ser o

1 Participaram da fundação da Universidade do Povo: Iguatemy Ramos, Amarilio Vasconcelos, Jaime Grabois, Paschoal Lemme, Aníbal Machado, Lia Correa Dutra, Artur Ramos, José Paulo Pimenta, Lemme Júnior, Aloísio Cisneiros, Letelba Rodrigues, Carlos Costa Pinto, Eugenia Álvaro Moreyra, Luiz Carlos Afilhado, Oscar Niemeyer, Astrogildo Pereira (Tribuna Popular, 02 fev. 1946, p. 03). 
cerne. Para tanto, era preciso que fossem "convencidos da necessidade de se unir em associações de artes, profissões e resistência, como também deveriam ser aconselhados à sobriedade e ao combate ao álcool e à ociosidade" (Gomes, 2005, p. 68). Ações permanentes de qualificação eleitoral para os cidadãos a partir dos 18 anos, apoio a greves e agitações a fim de exercer pressão sobre o Estado pela garantia de oferta gratuita de instrução, serviços médicos, luz, água e barateamento de gêneros alimentícios de primeira necessidade conduziriam ao aceleramento do processo de transformação social. A sociedade defendida pelos socialistas demandava uma redefinição dos conceitos de liberdade e igualdade em contraposição ao individualismo liberal, tido como causa do isolamento e da opressão.

De meados dos anos de 1910 até início dos anos de 1920, o movimento anarquista teve atuação central na organização do movimento operário. Diferentemente dos socialistas, o projeto anarquista rejeitava o partido político como tática organizacional da classe trabalhadora, recusava o Estado como promotor do bem comum e propunha a sua eliminação em favor de outras redes de associações, de base comunitária, para administrar a sociedade. Sua estratégia revolucionária combinava luta política, por meio das greves, e educação da classe trabalhadora. Dessa maneira, em 1922, quando o PCB foi fundado, os anarquistas detinham a hegemonia no movimento operário (Gomes, 2005).

O surgimento do PCB deu-se num momento de difícil conjuntura nacional. Além da crise econômica e da instabilidade política, conflitos e revoltas armadas se intensificaram no país. Entre 1922 e 1926, Artur Bernardes governou o Brasil sob "estado de sítio" e uma grande ofensiva de repressão às oposições do regime foi instituída, dentre as quais, aquela destinada a conter o movimento operário. No interior desse processo, a disputa entre anarquistas e comunistas tornou-se acirrada devido à forte tradição anarquista no movimento sindical carioca; ainda que, nos idos de 1926, quase todas as lideranças anarquistas mais significativas já tivessem desaparecido. Assim, com o intuito de reorganizar o sindicato e lançar um "Bloco Operário” para concorrer às eleições para a Câmara dos Deputados em 1927, o PCB valeu-se de "métodos de propaganda tipicamente anarquistas, pois os trabalhadores gostavam e estavam com eles familiarizados. Era o caso da ação política através de atividades culturais, como o teatro" (Gomes, 2005, p. 159).

Após a eleição de Washington Luís para a presidência — o que significou a continuidade da política de alternância do poder dividida entre São Paulo e Minas Gerais - a ação repressiva do governo de Artur Bernardes não foi interrompida. Washington Luís temia que os tenentes e o movimento operário desestabilizassem o seu mandato e, assim, em 1927, aprovou a Lei Celerada. Por essa lei ficou permitido o fechamento de qualquer instituição que não seguisse as diretrizes ideológicas do governo. Nesse momento, o PCB foi posto na ilegalidade e sindicatos trabalhistas e clubes militares foram fechados.

Ocorrida a Revolução de 30, o governo provisório autorizou a reabertura dos sindicatos e em novembro daquele mesmo ano, cria-se o Ministério do Trabalho, Indústria e Comércio. A partir de então, o governo passou a atuar sobre os sindicatos a fim de levar as associações operárias para a órbita do Estado e, assim, concorrer com as esquerdas pela organização dos trabalhadores. 
Orientadas pela defesa de um modelo de sindicalismo corporativista, várias legislações foram sancionadas de modo a atrelar o gozo de benefícios sociais à associação do trabalhador em sindicados legalmente reconhecidos pelo governo. Por essa orientação buscava-se integrar grupos representativos do capital e do trabalho, reduzindo ou eliminando os conflitos de interesses e contendo demandas excessivas das partes, por meio da ação reguladora do Estado. O processo se deu de tal forma que, a partir de 1934, quase todas as leis que passaram a regular as relações de trabalho no Brasil foram promulgadas. Na análise de Gomes (2005), isso significava "que só quem tem ofício - quem é trabalhador com carteira assinada e membro de um sindicato legal - tem benefício" (Gomes, 2005, p. 179, grifos do original).

Desse modo, o trabalho das lideranças de esquerda tornou-se bastante difícil, já que era pouco atraente para os trabalhadores a adesão a associações independentes. Por certo, a instituição da Lei de Segurança Nacional, o fechamento da Aliança Nacional Libertadora (ANL) ${ }^{2}$ e a liquidação da Revolta Comunista também concorreram para alterar as relações entre o Estado e a classe trabalhadora. Após 1935 e se estendendo até os anos de 1940, os comunistas tornaram-se uma questão de segurança nacional. As lutas, nos sindicatos ou nas ruas, e qualquer outro tipo de ação independente no interior da classe operária foram interrompidos. No âmbito oficial desenvolveu-se uma série de iniciativas de promoção do bem-estar e da segurança dos trabalhadores combinadas com uma propaganda doutrinária do Estado Novo e uma política de aproximação do governo com o povo por meio da edificação de uma imagem positiva do trabalhador e a "glorificação do homem brasileiro".

A partir de 1943, o governo revitalizou os temas da sindicalização e do corporativismo a fim de transformar o movimento sindical em um interlocutor político. Mas essa operação guardava complexidades, visto que, para manter o movimento operário sob controle, pela via da representação sindical, o governo teria de garantir que essa representatividade fosse expressiva o bastante para ser capaz de fomentar a adesão e a mobilização do operariado. Ou seja, a campanha de sindicalização empreendida pelo governo deveria convencer sindicatos e lideranças das virtudes do sindicalismo corporativo num tempo em que o projeto político do Estado Novo começou a ser mais acentuadamente contestado. Dessa maneira, a tarefa do governo seria então angariar apoio social capaz de respaldar um regime que buscava a saída do autoritarismo. Daí a defesa de um corporativismo que se estruturava em articulação com as transformações do regime, muito embora a Carta de 37 permanecesse em vigência.

Ao final do Estado Novo, o PCB retorna à legalidade. Numa condução voltada para a união nacional e a paz, tendo em conta, inclusive, o fim da Segunda Guerra Mundial, a linha política do Partido consistia na união do proletariado com

2 Organização política de âmbito nacional de estreitas relações com o comunismo, fundada em 1935, cuja atuação culminou na Revolta Comunista de 1935. Sua plataforma incluía o combate ao "fascismo, ao imperialismo, ao latifúndio e à miséria". Segundo Rodrigo Patto Sá Motta (2002), “embora haja controvérsias sobre o papel desempenhado pelos comunistas na fundação da ANL, pouco se questiona o papel dirigente assumido pelo Partido Comunista na condução das atividades da frente aliancista” (Motta, 2002, p. 181). 
a burguesia progressista a fim de "acabar com os resquícios do fascismo e tirar o povo da miséria". ${ }^{3}$

No âmbito dessa orientação, o PCB empenhava-se em estimular a sindicalização com o propósito de fortalecer a unidade operária e enfrentar a política sindical do Ministério do Trabalho. ${ }^{4}$ Nesse espírito, em abril de 1945, criou-se o MUT, órgão de abrangência nacional que pretendia fazer frente à organização corporativista oficial. Sob a liderança de João Amazonas e de outros dirigentes sindicais, o MUT atuaria no fortalecimento da unidade sindical e estimularia a sindicalização dos operários.

Segundo Marcos Cesar de Oliveira Pinheiro (2014), o PCB também tinha como interesse fortalecer e ampliar os laços com os trabalhadores com vistas à "revolução democrática", entendida como etapa necessária ao processo de implantação do socialismo. Sindicatos e associações se tornaram centrais na educação e na organização da classe operária com vistas à democracia brasileira.

Assim sendo, a UP foi fundada nesse contexto, ou seja, num momento particular de recrutamento dos trabalhadores para a sindicalização e de valorização da educação visando à sua qualificação para a participação.

\section{A EDUCAÇÃO DE ADULTOS COMO PRIORIDADE: BASES DA CONFORMAÇÃO DO PENSAMENTO SOCIAL DE PASCHOAL LEMME}

Além do importante papel desempenhado por Paschoal Lemme na idealização e organização da UP, o seu envolvimento nas lutas pela educação dos trabalhadores faz dele uma referência na história da educação de adultos. Entre os anos de 1928 e 1936, em meio às diversas funções que exerceu e atividades que realizou na Diretoria de Instrução Pública do Distrito Federal, trabalhou como professor e vice-diretor em cursos populares noturnos durante a administração de Fernando de Azevedo; organizou e dirigiu a educação de adultos do Distrito Federal na gestão de Anísio Teixeira; foi diretor da educação de adultos do Distrito Federal na gestão de Francisco Campos. Nos anos de 1933 a 1936, atuou junto à educação de adultos no contexto das suas atividades como inspetor de ensino primário e profissional do estado do Rio de Janeiro. Em 1938, por ocasião de concurso público do Minis-

3 De acordo com Alzira Alves de Abreu (2001), essa orientação, em verdade, não difere daquela que predominou durante quase toda a existência do PCB. A autora afirma que “com exceção de curtos períodos, a formação de frentes únicas dominou a sua linha política, principalmente após o ingresso de Prestes em suas fileiras. Do mesmo modo, o nacionalismo permeou de forma mais ou menos acentuada, dependendo do período, toda a sua atuação. A linha política que prevaleceu nos dois primeiros anos após o conflito mundial foi também ditada pela União Soviética, que preconizava a convivência pacífica com os Estados Unidos e demais países capitalistas"(Abreu, 2001, p. 4.268).

4 Assim como o governo, o PCB defendia a unidade sindical, mas era contrário ao modelo de sindicalismo baseado no corporativismo. Os comunistas defendiam o modelo de sindicato de indústria; o que correspondia a um sindicalismo de massas, voltado para as ações políticas e pressão parlamentar, a fim de influir nos problemas gerais de funcionamento do sistema social e econômico (Gomes, 2005). 
tério da Educação e Saúde (MES) para o cargo de técnico da educação, Lemme sistematizou as suas ideias e posições em relação ao tema por meio de monografia intitulada "Educação de Adultos — uma experiência de cursos de continuação, aperfeiçoamento e oportunidade realizada no Distrito Federal” (Lemme, 1938). Tendo sido aprovado no referido concurso, trabalhou como funcionário do Ministério da Educação até a sua aposentadoria, em 1961.

Enquanto isso, militou em diferentes agremiações, concedeu entrevistas, publicou artigos na imprensa, enfim, procurou colocar suas ideias e defesas em circulação. No contexto brasileiro da época, Lemme inovou ao difundir suas proposições políticas e educacionais fundadas na articulação entre educação, participação política e melhoria das condições econômicas dos trabalhadores como condição para "libertá-los das relações que os mantinham a margem do progresso e da civilização" (Lemme, 1937b, p. 08).

Paschoal Lemme defendia o investimento na educação de adultos como estratégia de enfrentamento das condições desumanizantes de exploração e reprodução do injusto sistema de classes. Considerava que a restrição da educação de adultos a cursos de alfabetização e técnicas de trabalho correspondia à oferta de uma formação comprometida com o fornecimento de conhecimentos e pessoal necessário à maquinaria produtiva do sistema capitalista em expansão. Ao reivindicar uma educação na qual fossem contemplados em seus direitos, os trabalhadores, os desempregados e os pobres, Lemme avaliava que a educação de adultos atuaria no processo de democratização da sociedade; condição que ele considerava sine qua non à democratização do ensino. Por entender que o trabalhador tecnicamente e culturalmente qualificado impulsionaria a equidade material e a participação, na base da conformação do pensamento social de Lemme, a educação de adultos era prioritária (Lemme, 1937a, 1937b, 1938).

Lemme inscreveu a educação de adultos numa noção abrangente de educação cujo processo é permanente ao longo da vida. Afirmou a capacidade de aprendizagem do adulto com base na assertiva de que o adulto aprende em função das suas necessidades reais; aprende muito menos do que poderia aprender porque, em parte, a sua capacidade de aprendizagem é subestimada, em outra, por supor que já passou da idade de instruir-se. Na perspectiva de Lemme, o analfabetismo e a pouca escolaridade dos trabalhadores eram situações inevitáveis, derivadas de uma estrutura social injusta e desigual que atingia os pobres, impedindo-os de se dedicarem aos estudos.

Com base nessas prerrogativas, na visão de Lemme a educação de adultos envolveria a oferta simultânea de ações formativas de natureza sistemática e assistemática. Avaliava que a educação escolar destinada aos adultos, na sua forma sistemática, não era capaz de suprir todas as suas necessidades de aprendizagem do adulto por centrar-se na oferta de cursos de alfabetização e de iniciação ao trabalho. Entendia que a rigidez organizativa da educação escolar terminava por dificultar a frequência dos trabalhadores às aulas. Além disso, considerava que o reduzido número de escolas destinadas aos adultos atingia uma pequena parcela da população concentrada nos centros urbanos existentes à época. 
Daí Lemme destacar a "obra de educação popular assistemática" como espaço privilegiado na formação dos adultos. Isso porque a flexibilidade curricular ampliaria as condições de acesso dos trabalhadores à educação e conferiria maior autonomia aos adultos na organização dos seus estudos tendo em vista as suas demandas. Além disso, a oferta de educação assistemática asseguraria a possibilidade de continuidade nos estudos bem como alargaria a capacidade de matrícula ao estender os espaços de formação aos sindicatos, às associações de classe, às cooperativas, aos clubes ou a outras agremiações. Assim, ao afirmar a educação assistemática como parte constitutiva da educação de adultos, fundamentalmente, Lemme afirmava os limites da educação sistemática na transformação social.

Ao lado da educação sistemática e assistemática, os "cursos de extensão cultural” completavam o modelo de educação de adultos idealizado por Lemme. Considerava que o trabalhador tinha direito à informação e à recreação. Assim sendo, atribuiu um papel pedagógico às artes e aos meios de comunicação na formação dos adultos. Concorriam para tal a instalação de bibliotecas públicas, fixas ou circulantes, museus, rádios, cinemas, teatros, exposições, palestras e demonstrações. Tratava-se de incorporar o trabalhador à civilização moderna, de modo que pudesse "gozar dos prazeres oferecidos pela cultura". Além do mais, considerava-se que a arte continha potencialidades revolucionárias e, nesse sentido, o acesso à cultura também atuaria em prol da democratização da sociedade. Portanto, era preciso estendê-la às massas (Lemme, 1937b).

Orientado por esse ponto de vista, em termos práticos, Paschoal Lemme organizou e dirigiu a educação de adultos no âmbito do poder público local do Distrito Federal nos anos de 1930 e na década de 1940, sob a chancela do PCB, atuou na fundação da UP. Inspiradas nas "universidades populares" da Europa "estabelecimentos que preenchiam os vazios que o ensino deixava na cultura dos trabalhadores dedicando-se ao intercâmbio de ideias e aprofundamento de problemas filosóficos, políticos e econômicos da vida social e nacional" (Lemme, 1937a, p. 12) - as duas experiências guardam muitas afinidades entre si e, de certo modo, a UP representou a continuidade dos trabalhos iniciados por Lemme no Distrito Federal e que foram interrompidos com a sua prisão, ocorrida em $1936 .^{5}$

5 À época, Paschoal Lemme era responsável pela Diretoria de Educação de Adultos e Difusão Cultural; setor da Diretoria de Instrução Pública do Distrito Federal. Sua prisão se deu em meio às investigações realizadas pela Comissão Nacional de Repressão ao Comunismo em decorrência da Revolta Comunista de 1935. De acordo com relatório da Polícia Política, o programa dos cursos de educação de adultos da União Trabalhista — organização operária com cerca de 70 sindicatos a ela filiados — proposto por Valério Regis Konder, Paschoal Lemme e Edgar Süssekind de Mendonça, havia sido enviado a Arthur Ernest Ewert e Luís Carlos Prestes para aprovação. Consta ainda que os referidos proponentes eram membros do quadro social da ANL, com destacada atuação. A isso, o relatório acresce que fora apreendido um documento escrito de próprio punho e assinado por Prestes pelo qual indicava os nomes de Paschoal Lemme e Valério Konder, dentre outros nomes relacionados, como as pessoas com os quais os revoltosos podiam contar, por ocasião da Revolta Comunista (Relatório da Polícia Política, 1937). Como resultado, em 14 de fevereiro de 1936, após o expediente dado na Diretoria de Educação de Adultos e Difusão Cultural, Lemme foi detido e preso por um período de 16 meses. 
Por certo, a experiência do cárcere foi dolorosa. Um tempo de incertezas, humilhações, sofrimentos, protestos, tensões, frustrações e de aprendizados. Percebendo que o período na prisão se estenderia, Lemme (2004) conta que ele, Tavares Bastos, Frederico Carpenter, Graciliano Ramos, Agildo Barata, dentre vários outros, ocuparam-se com jogos, leituras e com a organização de cursos e palestras. Os temas eram variados e cada um contribuía com os conhecimentos de que dispunha. Além dos cursos e das palestras, instalaram ali uma "universidade popular", para a qual Lemme foi escolhido para "reitor". Nessa instituição "sui generis", ele disse que "cada um ensinava o que sabia e aprendia o que ignorava" e que os presos analfabetos que passaram algum tempo no "pavilhão dos primários" foram todos alfabetizados (Tribuna Popular, 11 mar. 1947, p. 03).

Lemme avaliava que a sua prisão havia sido uma injustiça. Dias após ser libertado, foi convidado a proferir a conferência "Educação de Adultos" numa associação de professores das escolas noturnas municipais do Distrito Federal. Naquela ocasião, afirmou sua disposição em seguir ativo na luta pela educação dos trabalhadores.

(...) É insuficiente todo o esforço pela cultura popular que não persiga suficientemente o objetivo de introduzir o proletariado na comunidade cultural. Tres aulas de história do trabalho, dadas numa associação operária, com essa unica intenção, custou-nos 16 mêses e dois dias de segregação do convívio social e um processo que para honra da civilização brasileira foi considerado iniquo. Queremos afirmar aqui, de passagem, que qualquer que seja os obstaculos postos por forças interessadas em manter a classe operaria na ignorancia, impelindo-a, pois, para a revolta, continuaremos absolutamente dispostos, agora, mais do que nunca, a nos dedicarmos sem desfalecimentos à obra da educação do povo de nossa terra. (Lemme, 1937a, p. 09)

As convicções de Lemme e o seu apreço a valores igualitários, à democracia, à liberdade de pensamento e aos princípios da moderna pedagogia estiveram no âmago das suas figurações. ${ }^{6} \mathrm{Nasceu}$ e cresceu em ambiente familiar de orientação espírita; o que significava, naquela época, ter sido educado sob

6 Segundo Norbert Elias (2001), a figuração se refere à relação de interdependência entre indivíduos. Para o autor, a historicidade de cada indivíduo, da infância à idade adulta, é a história das suas relações de interdependência com outras pessoas e funções e contém a síntese daquilo que chamamos de sociedade. $\mathrm{O}$ estudo dessa historicidade é, por sua vez, a chave para a compreensão das ideias e dos comportamentos humanos, num dado contexto social. Com base na proposição eliasiana, a compreensão da trajetória de Paschoal Lemme se deu de modo enredado a fim de que a sua historicidade emergisse com a história do seu tempo e em relação aos grupos sociais dos quais participou. 
a ordem da razão e da ciência em detrimento do preceito religioso. ${ }^{7} \mathrm{Na}$ vida profissional foi defensor da escola pública, democrática e laica. Especialmente nos anos de 1920 e 1930, além da sua participação como signatário do Manifesto dos Pioneiros da Educação Nova, de 1932, Lemme foi ativo colaborador nas reformas educacionais do Distrito Federal, exercendo cargos de confiança nas gestões de Fernando de Azevedo e de Anísio Teixeira. Identificado com as ideias marxistas, passou a reconhecer a existência de uma íntima relação entre as desigualdades sociais e as desigualdades educacionais. ${ }^{8}$ Ao se aproximar da militância comunista, assumiu definitivamente a convicção de que qualquer proposta educacional de aspiração emancipatória não poderia dissociar-se da

7 Fortemente socializado pela doutrina espírita, Lemme aprendeu que o "espiritismo kardecista era uma ciência universal" (Lemme, 2004, p. 144). Ocorre que, nas suas origens, o espiritismo aspirou reconhecimento acadêmico por considerar a alma como uma questão científica. Em função disso, proclamou-se instância da ciência experimental. Pretendeu demonstrar que, por meio da atividade mediúnica, era possível provar a existência dos espíritos e a sobrevivência da alma após a morte. Hippolyte Léon Denizard Rivail, que depois adotaria o nome de Alan Kardec, foi o codificador do espiritismo na França. De acordo com Mary del Priore (2014), em 1854, Rivail passou a se interessar pelo magnetismo e pelos fenômenos sobrenaturais. Estudou de forma racional e científica a fim de explicar porque as mesas volantes se moviam. Ao participar de sessões organizadas por sonâmbulos e seus magnetizados, passou a receber uma série de anotações oferecidas pelos sonâmbulos bem como a acrescentar informações a partir de questões que ele propunha às pessoas em transe. Em 1857, com o pseudônimo de Alan Kardec, publicou O livro dos espíritos, resultante dos seus estudos e cujo objetivo era apresentar as bases para o entendimento da "ciência espírita". Um ano depois, Kardec fundou a Revue Spirite, ainda hoje em circulação.

8 É interessante observar aspectos da atuação de Lemme no movimento de renovação pedagógica dos anos 1920 a 1930. Por exemplo, existe a suspeita de que Lemme e outros educadores socialistas tenham participado como coautores ou influenciado indiretamente na redação do Manifesto dos Pioneiros da Educação Nova. Segundo Luiz Antônio Cunha (1994), o texto do Manifesto contém uma série de ideias contraditórias em relação à educação e à sociedade e foi assinado por socialistas como Edgar Süssekind de Mendonça, Hermes Lima, Roldão Lopes de Barros e o próprio Paschoal Lemme. Quanto a Lemme, acrescenta que "se ele não era um marxista assumido, à época, pelo menos já tinha simpatias e contatos próximos, inclusive familiares, com comunistas" (Cunha, 1994, p. 139). No entanto, o posicionamento de Lemme não o colocava em confronto com a condução dos administradores das reformas educacionais do Distrito Federal; reformas essas comumente tidas como liberais na literatura especializada. Conforme Dermeval Saviani (2008), "àquela época não havia incompatibilidade entre 'liberais' e 'marxistas' na formulação de um projeto educacional. (...) todos os progressistas, inclusive os marxistas, tenderam a endossar o credo escolanovista" (Saviani, 2008, p. 92). Assim, a atuação de Lemme na educação de adultos esteve inscrita nesse contexto. No limite das possibilidades impostas à revolução operária, trabalhar em prol da revolução burguesa foi o caminho encontrado por ele. 
ordem social mais ampla. Nessa trajetória, Lemme tornou-se um educador de esquerda e intelectual ${ }^{9}$ antifascista.

\section{A VOZ DE PASCHOAL LEMME JUNTO AO PARTIDO COMUNISTA DO BRASIL E SUAS RESSONÂNCIAS NA CRIAÇÃO DA UNIVERSIDADE DO POVO}

Em 1945, Lemme foi convidado a colaborar na parte relativa à educação constante no programa de governo do PCB tendo para isso se baseado no texto "A situação do ensino no Brasil”"(1945), de sua autoria. ${ }^{10}$ Assim ele se pronunciou quanto ao convite:

Certo dia desse mesmo ano de 1945, recebo um recado. Não me recordo bem de onde e de quem. Informava-me que Prestes deveria pronunciar um discurso sobre o programa de governo da Aliança Nacional Libertadora e que nele, naturalmente, deveria figurar alguma coisa referente aos problemas de educação e ensino. Consultavam-me se eu estaria disposto a colaborar redigindo algumas sugestões. Respondi ao emissário que não gostaria de assumir essa responsabilidade sozinho e indicava como companheiro para esse fim o professor Edgard Süssekind de Mendonça. Disseram-me que eu contaria com a colaboração de Campos Melo, um economista que, segundo creio, era filiado do Partido Comunista. Edgard, sempre às voltas com seus problemas de saúde, agravados com a permanência na prisão, não pôde nos ajudar. Redigi, então, sozinho, o trabalho que aparece em seguida e que foi entregue pessoalmente por mim a Prestes, nesse primeiro encontro que tive com ele, na presença de Campos Melo. (...) Expliquei-lhe a natureza do trabalho e disse-lhe que procurara fazer um panorama geral da situação do ensino na época, nos seus vários graus e modalidades, mas num discurso, cujo sumário ele me apresentava, naturalmente apenas referências muito gerais deveriam aparecer sobre esses problemas de educação e ensino. E foi o que aconteceu. (Lemme, 2004, p. 33) ${ }^{11}$

9 O conjunto das atividades e ações realizadas por Lemme permite associá-lo à ideia de um intelectual ao modo proposto por Jean-François Sirinelli (2003). De acordo com o autor, o intelectual é aquele indivíduo engajado na vida da cidade cuja "notoriedade eventual ou sua especialização, reconhecida na sociedade em que vive (especialização esta que legitima e mesmo privilegia sua intervenção no debate da cidade), põe-se a serviço da causa que defende" (Sirinelli, 2003, p. 243).

10 Durante o período em que o PCB esteve na legalidade, ou seja, entre 1945 e 1947, Paschoal Lemme assessorou o partido junto à Câmara Federal e na Assembleia Legislativa do Distrito Federal nas questões relativas à educação (A Manhã, 21 nov. 1946, p. 02).

11 Neste trecho Lemme afirma que o seu trabalho foi realizado com a finalidade de subsidiar o pronunciamento de Prestes "sobre o programa de governo da Aliança Nacional Libertadora”. No entanto, deve ter havido alguma confusão de Lemme ao redigir suas memórias, pois, como sabemos, a ANL havia sido fechada desde final de 1935. Por sua vez, no ano de 1945, que o autor faz a referência, Prestes era secretário-geral do PCB, posição em que se manteria até 1980. 
O texto "A situação do ensino no Brasil", em que Lemme baseou a colaboração ao $\mathrm{PCB}$, centra as análises relativas à educação de adultos na articulação entre analfabetismo e desigualdade social. Na perspectiva do autor, a privação dos trabalhadores de participarem da vida política do país é uma das consequências da relação entre desigualdades escolares e desigualdades sociais.

(...) mínimo de educação elementar é, ainda, uma aspiração de realização mais ou menos longínqua para um grande número de países que ainda não puderam se libertar de formas atrasadas de relações econômicas e mantêm, por isso, grandes massas de suas populações inteiramente à margem do progresso, da civilização, impossibilitados pela miséria em que vivem e pela dispersão em vastas áreas dos respectivos territórios, de procurarem a escola primária e nela permanecerem por tempo suficiente, de modo a receberem essa educação básica. (...) Conta assim o Brasil com mais da metade de analfabetos em sua população adulta, a partir justamente da idade em que os indivíduos devem participar ativamente da vida econômica e política do País. E bem verdade que tal situação não é uniforme para todo o País, apresentando variação bastante grande entre percentagens extremas que vão de $17,80 \%$ de analfabetos no Distrito Federal a 77,40\% em Alagoas. Nem por isso deixa de ser menos chocante, pois mesmo essa percentagem mínima para a capital do País representa um contingente acima de 200 mil indivíduos, de 18 anos e mais, agora privados, iniquamente aliás, de participar da vida política do País, de acordo com a atual legislação eleitoral. (Lemme, 1945 apud Lemme, 2004, p. 35)

A relação entre educação e participação política foi novamente destacada por Lemme, ao analisar o tema da alfabetização de adultos na I Convenção Popular do Distrito Federal, evento organizado pelo PCB, em 1945, com o objetivo de discutir e apresentar sugestões ao poder público quanto aos problemas do Distrito Federal (educação, saneamento, habitação, transportes). Nessa convenção, após o estudo das teses apresentadas pelos membros das diferentes comissões, cada qual apresentou um relatório síntese dos trabalhos e as proposições retiradas.

No que se refere à alfabetização de adultos, Lemme, na condição de relator da Comissão de Problemas de Educação, ${ }^{12}$ analisou a proibição do voto pelo analfabeto e circunscreveu a emergência do tema à necessidade de habilitar o adulto à participação política.

Alfabetização de adultos

É esse também um dos assuntos expressamente incluídos no ternário da Convenção e, por isso mesmo, abordado em quase todas as teses. Deveria tal proble-

12 A Comissão de Problemas de Educação era composta por Paschoal Lemme, Lia Correia Dutra, Dante de Brito, Domingos dos Santos e Valdir Duarte (Diário de Notícias, 11 jul. 1945, p. 04). Seguiu atuante após a realização da I Convenção Popular do Distrito Federal. Em 1946, encontrava-se formada pelas professoras Maria Alexandrina Paca, Vera Barbosa Coutinho, Noemia Sales, Brites Álvares Barata, Ana Braga, Vera de Sousa, Ubaldina Dias Jacaré, Paschoal Lemme e Fernando Segismundo (Diário de Notícias, 14 abr. 1946, p. 08). 
ma merecer um estudo extenso, mas tratando-se de uma questão de emergência, dada a sua significação política no presente momento, reduziremos essa parte do relatório ao essencial. Não poderemos, entretanto, ao tratar desse problema, deixar de lamentar, como já o fizeram tantos outros, o fato de o Código Eleitoral ter negado o direito de voto ao analfabeto nas próximas eleições. Medida profundamente injusta, iníqua mesmo. Injusta porque o analfabeto é um indivíduo que, como qualquer outro, trabalha, produz, constitui família, paga impostos, educa os filhos, enfim, pratica todos os atos da vida civil e, muitas vezes, com maior eficiência do que muitos letrados. Para isso são obrigados constantemente a opinar, decidir, escolher, não nos parecendo que todos esses atos que realiza como homem e cidadão sejam mais fáceis de executar do que a escolha consciente de representantes para a administração ou para as assembleias legislativas. Talvez mesmo, como já se disse, o fato de o analfabeto votar poderia redundar em que fossem adotadas mais rapidamente medidas práticas para que o País saísse da situação em que ainda se encontra, de contar, ainda em 1945, entre os 22.935 .378 habitantes de 18 e mais anos de idade, com mais de metade de analfabetos, ou seja, aproximadamente, 12 milhões. (Lemme, 1953, p. 110-111)

Na visão do relator, o adulto analfabeto é aquele pertencente à parcela pobre da população, que por suas condições não pode estudar ou teve de abandonar os estudos ou se esqueceu do que aprendeu, "por falta de uso". Trabalha arduamente e julga que o saber ler e escrever não the rende grandes vantagens imediatas. Ao mesmo tempo, a condição de analfabeto o envergonha e, com isso, procura escondê-la. Em função disso, recomenda-se que o professor seja conhecido e que tenha alguma ligação com aqueles que se iniciam na aprendizagem, de modo a atenuar possíveis constrangimentos e desconfianças.

Evidentemente, deve tratar-se de pessoas pertencentes às camadas mais pobres, empregados domésticos, frequentemente trazidos do interior, operários não qualificados, moradores das favelas e da zona rural, que, por suas condições, não puderam frequentar escolas primárias nas idades próprias ou abandonaram o curso ainda não alfabetizados, ou, ainda, por falta de uso, foram esquecendo o pouco que conseguiram aprender. (...) São pessoas, em geral, que chegam à tarde ou à noite cansados do trabalho árduo do dia, moram em lugares pouco acessíveis e nem sempre encontram vantagem de ordem prática imediata no fato de aprender a ler e escrever, ou melhor, julgam pouco compensador um esforço tão grande como o que têm que empregar para aproveitar alguma coisa do ensino. Por outro lado, a tarefa de ensinar a pessoas de condição tão diversa tem que ser praticamente individual. Isso tudo, aliado ao fato de que, em geral, o analfabeto adulto se envergonha de sua condição e procura escondê-la, torna particularmente difícil o trabalho dos que desejam se empenhar nessa obra patriótica, pondo à prova toda sua dedicação. Há, além disso, o problema dos métodos a adotar para obter os melhores e mais rápidos resultados, porém tal aspecto da questão não poderá ser tratado convenientemente aqui. Alguns Comitês Populares já estão empenhados em resolver essa parte do proble- 
ma, tendo procurado o auxilio de pessoas que se dedicam ao estudo desses assuntos e já vão pondo em execução algumas medidas de ordem prática sugeridas por elas. Nesse sentido, sabemos que já está sendo utilizado um material para aprendizagem da leitura para adulto, organizado pelo Dr. Moisés Xavier de Araújo, e que deverá ser posto, brevemente, à disposição de todos os interessados. Quanto aos professores, parece que a experiência vai mostrando que a escolha deverá ser feita, até onde for possível, entre pessoas mais ligadas à própria classe dos que estão necessitando da aprendizagem, pois isso, de certa forma, diminuirá o constrangimento e afastará as desconfianças com que são sempre recebidas as pessoas de condição muito diferentes. (Lemme, 1953, p. 112)

De acordo com os encaminhamentos, no relatório da Comissão de Problemas de Educação à I Convenção Popular do Distrito Federal consta que a alfabetização de adultos deveria ser enfrentada sob duas óticas: a da emergência e a da permanência. No âmbito da emergência caberia identificar os adultos analfabetos e mobilizá-los para a instrução. Para essa "obra patriótica", além da propaganda veiculada pela imprensa e pelo rádio, seria importante contar com a participação de associações, clube e entidades na cessão de espaço físico destinados à instalação de centros de alfabetização e arrecadação de material. Já na esfera da permanência, o poder público municipal deveria investir na extensão e manutenção de escolas noturnas aos adultos. Numa clara referência ao modelo do Distrito Federal na administração de Anísio Teixeira, quando Lemme organizou e dirigiu a educação de adultos, essas escolas deveriam oferecer cursos que contemplassem a alfabetização e os cursos de continuação e aperfeiçoamento. O relatório também referenciou a experiência do Serviço Nacional de Aprendizagem Industrial (SENAI) e, com isso, incluiu a formação profissional no âmbito da educação de adultos (Lemme, 1953).

Alguns meses após a I Convenção Popular do Distrito Federal é que se deu a criação da UP. Sem fins lucrativos, a instituição funcionava por meio da contribuição dos seus associados e de recursos angariados em festividades e exposições. Tinha como objetivo atuar na "elevação do nível cultural e no desenvolvimento da educação do povo por meio do ensino, da preparação técnica e do alargamento da cultura, especialmente da classe trabalhadora" (Tribuna Popular, 24 mar. 1946, p. 03).

Inicialmente a Universidade ministrará cursos regulares e avulsos de alfabetização, científicos e profissionais; promoverá conferencias sobre assuntos de interesse nacional e audições de concertos de caráter popular; organizará bibliotecas no centro da cidade e nos bairros; explorará o uso da radiofonia e do cinema sob os aspectos educativo, recreativo, documentário e social; estimulará a formação de grupos de pesquisadores e estudiosos dos problemas nacionais. (Tribuna Popular, 24 mar. 1946, p. 03, 06)

A instalação da UP foi registrada por Jorge Amado, em sua coluna da Tribuna Popular. Na saudação do colunista, a presença de Lemme na tarefa a ser empreendida pela UP foi destacada. 
A instalação, na sexta-feira, da Universidade do Povo prova, antes de tudo, que os intelectuais brasileiros não se mantem indiferentes ante os graves problemas do Brasil. Entre a massa trabalhadora que participou do ato estavam escritores, artistas, pedagogos, figuras como Portinari, Niemeyer, Paschoal Lemme. E disseram das finalidades a que se propõe a nova Universidade, muito diversa, sem dúvida, daquelas que se dirigem à formação das falsas elites enquanto a grande maioria do povo vive analfabeta. No seu discurso, Prestes, ao louvar a iniciativa, mostrou quais as grandes dificuldades que a Universidade do Povo e seus diretores iriam enfrentar. As nossas populações vivem na miséria, sub-alimentadas e tudo as afasta da cultura. Mostrou como o problema da educação está ligado ao problema da democracia e da solução dos problemas econômicos. E abriu também para a Universidade, ao mesmo tempo que apontava a dificuldade a vencer, as perspectivas da grande obra que ela pode realizar. É inegável a importância da obra a qual Paschoal Lemme e Jaime Grabois e tantos outros abnegados patriotas estão dando o melhor do seu esforço. A educação popular é tarefa que deve figurar entre as mais urgentes a que se propõem todos que tiveram condições para adquirir os bens da cultura. Trazer até as grandes massas esses conhecimentos, desde os mais elementares até as últimas conquistas da ciência, eis o que pensam realizar os fundadores da Universidade do Povo. Desse canto de coluna, desejo fazer um apelo a todos os escritores e artistas democráticos para que tragam a sua contribuição à grande obra recém-iniciada. Aqueles que possam ensinar alguma coisa, dar livros, ajudar materialmente, conseguir locais, interessar alunos, que o façam. É sempre possível ajudar. E ajudar uma obra como essa é ajudar o Brasil e o seu povo. (Tribuna Popular, 31 mar.1946,p. 03)

Diferentemente das “escolas de partido", voltadas para a formação de quadros, Alfredo Wagner Berno de Almeida (1983) afirma que "a UP cumpria o papel de divulgação ideológica mais ampla", ou seja, "não foi pensada para educar exclusivamente os militantes partidários"(Almeida,1983,p.38).O quadro docente da UP era composto por professores, técnicos em educação, artistas, jornalistas e escritores interessados no programa educativo e cultural da instituição. Os cursos oferecidos eram os mais diversos - desde assistência materna, formação de parteiras práticas, torneiro mecânico, taquigrafia, inglês, russo, direito trabalhista até aqueles dedicados ao teatro, à pintura, à arquitetura e a problemas de filosofia e sociologia. Funcionavam de modo descentralizado, mas a instituição tinha sede própria. ${ }^{13} \mathrm{Com}$ a sua fundação, a UP também assumiu a tarefa de prestar assessoria aos cursos de alfabetização de adultos desenvolvidos pelos Comitês Democráticos Populares. ${ }^{14}$

13 A sede da UP funcionou provisoriamente à Rua Buenos Aires, 70 - $4^{\circ}$ andar antes de ter sido instalada na Avenida Aparício Borges, 201 - 4º andar/sala 401 (Tribuna Popular, 02 jun. 1946, p. 03).

14 Dentre as ações dos Comitês Democráticos Populares, no âmbito da educação popular "o carro-chefe era a alfabetização de adultos (...) que tinha como preocupação formar eleitores e qualificar o eleitorado a fim de torná-lo capaz de identificar entre os candidatos aos postos eletivos àqueles merecedores da confiança popular. Nessa orientação também realizavam várias atividades culturais como teatro amador, sessões de cinema e exposições" (Pinheiro, 2014, p. 41). 
De certo modo, o trabalho desenvolvido pela UP integrava o clima propiciado pela abertura do processo político que permitiu ao $\mathrm{PCB}$ atuar na legalidade. Tenho como hipótese que, ao organizar e colocar em funcionamento uma dada estrutura educacional, a UP competia como proposta ideal de educação a ser destinada aos adultos em oposição, sobretudo, à Campanha de Educação de Adolescentes e Adultos (CEAA). ${ }^{15}$

Um exemplo disso pode ser identificado na participação de Lemme e Fernando Segismundo no I Congresso Nacional de Educação de Adultos como representantes da UP. Naquela ocasião, os representantes da UP tiveram a oportunidade de explorar o tema da educação de adultos, recordar a experiência desenvolvida na gestão de Anísio Teixeira e apresentar o trabalho realizado pela UP na expectativa de receber o amparo do poder público para dar prosseguimento às atividades ali realizadas.

\section{(...) Representando com meu colega Fernando Segismundo, a Universidade do Povo,} tivemos a oportunidade de expor aos congressistas e autoridades presentes o caráter e as realizações dessa instituição que, num ano apenas de funcionamento, vem proporcionando ensino gratuito a mais de 2.000 pessoas, em cursos de continuação e aperfeiçoamento dos mais variados, desde os de mecânica até os de inglês, cursos do art. 91, cursos de extensão universitária, devendo lançar-se agora numa ampla campanha de alfabetização de adultos para a qual está preparando monitores e dispõe de um instrumento valioso: a cartilha para o ensino de adultos, organizada pelo técnico de educação doutor Moisés Xavier de Araújo. (...) Minha posição perante o Congresso era, entretanto, particular. Responsável na administração Pedro Ernesto-Anísio Teixeira por um setor de educação de adultos então criado em novos moldes, fui instado por colegas e auxiliares dêsse trabalho para que defendesse aquela obra, e não pudemos deixar de atendê-los. Aproveitei então a oportunidade para dizer-lhes de público que se houve interrupção brusca no sentido daquela obra, se de minha mesa de chefe de serviço fui levado à prisão por 16 meses pelo crime de cooperar num amplo movimento de educação do povo, se a denúncia viera estampada com as tortuosidades de sempre no órgão nazista do Brasil a "Ofensiva", se o processo no Tribunal de Segurança se baseava no fato "gravíssimo" de eu ter dado 3 aulas de história do trabalho na União Trabalhista como parte de um programa considerado "marxista”, tudo isso era muito próprio dessa época de ascensão do fascismo no mundo, do preparo entre nós do golpe de 37 que nos vilipendiou por quase 10 anos, mas que

15 A CEAA, primeira iniciativa da União destinada à educação dos trabalhadores, funcionou entre os anos de 1947 a 1963. Nasceu da regulamentação do Fundo Nacional do Ensino Primário (FNEP), na qual a educação dos adolescentes e adultos foi contemplada com amplos recursos. Paralelamente ao trabalho educacional, a CEAA também planejou atuar na educação dos adultos por meio de "missões rurais" compostas por equipes multidisciplinares "aptas a desenvolverem programas integrados de formação nos setores agropecuário, médico-sanitário, familiar, de economia doméstica, educação geral e serviço social". No entanto, autores como Celso Rui de Beisiegel (2004) e Vanilda Paiva (2003) consideram que, embora a CEAA estivesse orientada por uma perspectiva mais ampliada de educação, na prática a campanha se concretizou por uma abordagem do problema da educação de adultos restrita à alfabetização e ao domínio de técnicas de trabalho. 
não obstante tudo isso não desertáramos. (...) Restituído à liberdade depois de assim "reeducado" não hesitamos em disputar um lugar de técnico de educação do Ministério da Educação, em concurso público, com uma tese em que relatávamos aquelas mesmas experiências realizadas no Distrito Federal sobre educação de adultos e onde dizíamos: 'o problema da educação do adulto, da incorporação desse imenso capital humano à civilização assume entre nós, sob todos os aspectos, tais proporções que não será exagero afirmar que ultrapassa em premência e importancia a própria obra da extensão do ensino elementar para indivíduos em idade escolar'. Não imaginávamos então que essa afirmação, considerada em tanto avançada no momento, viesse a ser dolorosamente confirmada pelo recenseamento de 1940 que apurou entre os indivíduos de 18 anos e mais de idade a percentagem alarmante de 54,68\% de analfabetos, (...) justificando agora uma campanha nacional de educação de adultos. Em seguida, no Instituto de Estudos Pedagógicos, na Associação Brasileira de Educação, na Convenção Popular do Distrito Federal, na imprensa diária ou especializada ou no Museu Nacional não abandonamos um instante sequer a luta pela educação do povo, sem desliga-la porém de sua base, do problema político de emancipação econômica do país. (...) Essa continua a ser a nossa posição perante o problema, o que nos faz desconfiar que o Ministério da Educação, lançando uma campanha de educação de adultos que considera de "salvação nacional" talvez não esteja pesando bem todos os fatores que poderão torná-la vitoriosa, a menos que estejamos enganados, pois desconhecemos os detalhes da execução do plano. De qualquer forma, porém, (...) fazemos votos para que a administração municipal retome com vigor a obra interrompida. (Tribuna Popular, 11 mar. 1947, p. 03)

No entanto, ao que parece, a representação da UP foi ignorada em suas colocações. De acordo com Vanilda Paiva (2003), na ocasião do lançamento da CEAA as sugestões e as experiências educativas comunicadas pelas esquerdas marxistas ao I Congresso Nacional de Educação de Adultos não foram sequer transcritas nos anais do evento. Haja vista a vinculação da UP com o PCB, o fato não causa estranheza, já que, segundo a mesma autora, dentre os fundamentos políticos da CEAA constava também o "combate às ideologias estrangeiras".

Embora sofrendo algumas invasões policiais ao longo da sua existência, a UP sobreviveu à repressão ${ }^{16}$ até o ano de 1957, quando foi extinta. Antes de ser extinta,

16 Em sintonia com as condições internacionais que apresentavam os primeiros sinais da Guerra Fria, os magistrados do Tribunal Superior Eleitoral (TSE) tinham dúvidas sobre o caráter democrático do programa dos comunistas. Em maio de 1947, o TSE julgou procedente a sindicância instalada para investigar denúncias de irregularidade no estatuto do PCB. Em decorrência das investigações, o partido fora considerado um partido estrangeiro sob a alegação de que se tratava do "Partido Comunista do Brasil", e não de um "Partido Comunista Brasileiro". Daí determinou-se o encerramento das suas atividades e uma onda de repressão policial sobre os núcleos comunistas foi desencadeada. Em 1948, os mandatos de parlamentares comunistas foram cassados e o Ministério do Trabalho interveio nos sindicatos considerados sob o controle comunista. A Confederação dos Trabalhadores do Brasil (CTB), outrora MUT, foi fechada (Abreu, 2001). 
teve seu nome substituído por Escola do Povo. Registrada como instituição municipal de ensino do Rio de Janeiro, conforme veiculado pelo jornal Imprensa Popular, a Escola do Povo recebia subvenção do poder público por meio de verbas da União e do município, além das contribuições dos associados. Como os cursos oferecidos pela escola eram variados e organizados em função das demandas, a diversificação das suas atividades incluiu, por exemplo, curso prático de jornalismo sindical, coral popular, teatro de bonecos, "conjunto folclórico" com aulas de maracatu, candomblé, folia de reis, samba, dentre outros, além do Centro Experimental de Estudos Cinematográficos, que oferecia cursos, oficinas e atividades afins.

De acordo com a imprensa do PCB, o fechamento e a dissolução da então Escola do Povo, ocorridos no governo de Juscelino Kubitschek (1956-1961), foram motivados por denúncias da Cruzada Anticomunista que criticaram as ligações entre a instituição e o PCB. No entanto, a autoria das acusações foi assumida pela Frente da Juventude Democrática, que apontava a "Escola do Povo como um dos mais ativos núcleos comunistas da capital da República, disfarçado em estabelecimento de ensino, canto, violão, francês e inglês..." (Jornal do Brasil, 02 mar. 1957, p. 07).

É provável que Paschoal Lemme tenha se mantido ativo junto à Escola do Povo até a época do seu fechamento, mas só foi possível acompanhar a sua vinculação com a instituição até 1952. Consta que em abril daquele ano, quando Lemme compunha o Conselho Técnico-administrativo da Escola do Povo, este Conselho veio a público manifestar repúdio às perseguições "policial-fascistas" sofridas pela escola, quando em dias anteriores havia sido invadida e teve suas atividades interrompidas. No ato de condenação expresso pelo Conselho consta ainda que, além de apreenderem dois dos seus professores, cartilhas, fichários e papéis oficiais daquela instituição também haviam sido recolhidos pela polícia (Imprensa Popular, 20 abr. 1952, p. 04).

\section{"AGORA QUE VOCÊ JÁ SABE LER E ESCREVER..." ALFABETIZAÇÃO DE ADULTOS E PARTICIPAÇÃO POLÍTICA NO MATERIAL DIDÁTICO DA UNIVERSIDADE DO POVO}

No que se refere aos cursos de alfabetização de adultos, o trabalho da UP tinha como base didática a cartilha "Chave de leitura (para adultos)", elaborada por Moisés Xavier de Araújo, membro da Associação Brasileira de Educação (ABE) e um dos signatários, com Lemme, do Manifesto dos inspetores (A reconstrução educacional do estado do Rio de Janeiro: manifesto dos inspetores de ensino do estado do Rio de Janeiro ao magistério e à sociedade fluminenses), de 1934. Na apresentação da "Chave de leitura", o autor se dirige aos professores com o intuito de fornecer as orientações metodológicas de uso da Cartilha, mas também para afirmar a perspectiva político-pedagógica do material.

Aos professores

Em qualquer aprendizagem deve-se dar ao aluno o máximo de iniciativa. Esta verdade aplica-se evidentemente, à aprendizagem da leitura.

No caso de alunos adultos a falta de aplicação dêste princípio é um dos principais fatores de insucesso na direção da aprendizagem. Todos os que trabalham em clas- 
ses de adultos analfabetos observam frequentemente a atitude de constrangimento de muitos alunos em face do professor. O aluno evita recorrer ao mestre e não pode vencer sozinho as dificuldades que vão surgindo a cada momento; daí maior acanhamento, desanimo e abandono do curso. Muitos deixam de ingressar nos cursos de alfabetização porque não tem coragem de enfrentar a situação da sala de aula, onde teriam de depender a cada instante do auxílio e assistência do professor.

"Chave de leitura"é um material didático construído especialmente para adultos analfabetos e com o propósito de dar ao aluno o máximo de iniciativa pessoal de aprendizagem. O aluno deve usar a "Chave de leitura" como um instrumento de trabalho. As palavras devem ser "decifradas" com o auxilio dos desenhos; o confronto de palavras conhecidas permite "descobrir" elementos logo aproveitados em novas palavras. Como ponto de partida para a aprendizagem adotou-se, pois, a leitura de palavras. A palavra é, com efeito, o elemento mais simples dotado de significação e representável pelo desenho, mas em todas as lições há exercícios de leitura de frases inteiras, de conteúdo adequado à mentalidade adulta.

Está claro que nem sempre o aluno sairá das dificuldades sozinho: mas em todos os exercícios terá o sentimento de que não depende inteiramente de auxílio estranho. Os testes incluídos na "Chave de leitura" destinam-se à auto-verificação da aprendizagem e também à auto-correção e reaprendizagem. $\mathrm{O}$ aluno "toma a lição de si mesmo", corrige os erros e faz a revisão da matéria aprendida, e tudo numa atividade de leitura silenciosa, que é a leitura intelectual por excelência. A auto-verificação da aprendizagem é muito simples e deve ser explicada ao aluno desde as primeiras lições. $\mathrm{O}$ aluno deve cobrir os desenhos com um cartão ou um pedaço de papel e procurar ler as palavras ou sîlabas do teste; à medida que lê cada palavra, descobre o desenho correspondente "para ver se acertou". Os erros devem ser marcados com um sinal a lápis. A correção é feita imediatamente pelo próprio aluno à vista do desenho.

Os professores não devem esquecer que a aprendizagem da leitura não utiliza apenas material sistemático (lições graduadas, cartilhas, etc.). O aluno deve ser estimulado a ler em todas as oportunidades, fora das aulas e fora das lições dos livros ou cartilhas: cartazes, placas de rua, avisos, cabeçalhos de jornais, etc; tudo isso é um material de aprendizagem ocasional da leitura. (...) (Araújo, 1946, s.p.)

Do ponto de vista metodológico, "Chave de leitura" estava baseada no processo analítico-dedutivo no qual a percepção do todo antecede a percepção das partes. Nesse caso, a palavra e o seu desenho correspondente é que eram tidos como o todo do qual derivavam as sílabas seguidas da apresentação das suas respectivas "famílias silábicas"e da apresentação de um conjunto de palavras compostas pela junção das sílabas trabalhadas na lição. A cada lição, às novas "famílias silábicas" eram acrescidas aquelas anteriormente trabalhadas seguidas de textos que incluíam alguns dos vocábulos estudados, de modo a atribuir significação à palavra em um determinado contexto. Todos os textos eram apresentados em letra de imprensa, caixa-alta e cursiva. Além dos textos de cada lição, em alguns casos, há presença de provérbios, dias e meses do ano ou dias da semana. O alfabeto encontrava-se disposto ao final da cartilha com a apresentação das "letras estrangeiras" bem como uma relação de abreviaturas, provérbios e calendário. 
Em relação à proposta político-pedagógica, é interessante observar a consideração de Moisés de Araújo de que o adulto deveria ser estimulado a assumir o protagonismo do seu próprio processo de aprendizagem. Com isso, entende-se que o adulto não somente seria preservado de possíveis constrangimentos diante das suas dificuldades como também desenvolveria o sentimento de sentir-se capaz de aprender. Além disso, o autor afirma que "Chave de leitura" era um material "de conteúdo adequado à mentalidade adulta”. Nesse sentido, é bastante comum, nas lições que compõem a cartilha, encontrar palavras que rementem ao mundo do trabalho. ${ }^{17}$ Entretanto, apesar da defesa da presença do mundo adulto na cartilha, o mesmo não ocorre com as ilustrações, pois, às vezes, se fazem mais próximas do universo infantil. Dessa maneira, por exemplo, para corresponder ao vocábulo noite, nos deparamos com o desenho de uma Lua que tem nariz, boca e os olhos fechados.

Alinhado à orientação política do $\mathrm{PCB}$ de união nacional e paz, um tom nacionalista e patriótico perpassa as páginas de "Chave de leitura". As lições fazem referência a figuras que lutaram na Segunda Guerra, à Força Expedicionária Brasileira (FEB) e às Forças Armadas. O Brasil é exaltado por meio da sua natureza e de seu povo (frutas brasileiras, brasileiros ilustres, o Rio de Janeiro, o povo brasileiro). Contudo, é pela conclamação à participação política que a cartilha se esmera. A palavra-chave da primeira lição da cartilha é VOTO. A partir daí, numa sequência de lições, as palavras VOTO e POVO constituem a base para quase todos os textos de "Chave de leitura". Um exemplar desse empenho é o seu último texto.

17 Em 1945, o Ministério da Educação e Saúde publicou o trabalho de Nair Fortes Abu-Merhy (1945), "Cartilha para operário adulto - bases para sua organização", pelo qual a autora indicava aspectos a serem considerados na formulação de cartilhas destinadas à educação do adulto trabalhador. Não é possível afirmar que Moisés de Araújo tenha se utilizado dessa referência para proceder à seleção das palavras contidas nas lições de "Chave de leitura", mas é interessante verificar, por exemplo, a recomendação de Abu-Merhy sobre a necessidade de realizar uma pesquisa vocabular que correspondesse ao ambiente cultural do operário para compor as cartilhas. Essa pesquisa deveria ser capaz de distinguir os vocábulos levantados daqueles já existentes em outros materiais, apurados em livros, jornais e revistas lidos por operários já alfabetizados. Além disso, a autora sugere a realização de pesquisa de campo em regiões de operários para levantamento do vocabulário. Por meio de conversas com grupos de operários - entrevistas livres ou orientadas -, análise de produção de textos ou provas realizadas por adultos frequentes nas escolas elementares, esse levantamento deveria considerar o ambiente (familiar, profissional e recreativo) em que decorre a vida do operário, os motivos que os animam, seus interesses e preferências quanto a programas de rádio, filmes, livros, revistas, jornais e assuntos. Dessa coleta procederia a análise e sistematização dos vocábulos a compor uma cartilha tendo em conta os seguintes critérios: número de palavras, natureza das palavras, reino das palavras, organização das frases, gênero. Essas e outras interessantíssimas recomendações apontadas pela autora, além da semelhança com aspectos da proposição para a alfabetização de adultos que anos mais tarde seria formulada por Paulo Freire, dão uma boa noção do nível de particularidade com que a educação de adultos no Brasil vinha sendo discutida e estudada, sobretudo no que se refere à elaboração de material didático para os operários analfabetos ou em fase inicial de escolarização (Abu-Merhy, 1945). 
Agora você já sabe ler e escrever.

É preciso praticar bastante para ler e escrever melhor. Você deve ler e escrever diariamente. Assim você estará sempre aprendendo coisas novas.

Não se esqueça também dos seus companheiros que ainda não aprenderam a ler. Você aprendeu em pouco tempo. Êles também podem aprender rápidamente.

Lembre-se de que o Brasil é uma Democracia e todos os cidadãos teem o dever de votar.

Para votar é preciso alistar-se como eleitor, e para alistar-se é preciso saber ler e escrever.

Num paiz democrata todos devem saber ler e escrever para votar.

Você agora sabe ler e escrever. É um cidadão livre de uma sociedade democrata. Aliste-se como eleitor. $\mathrm{O}$ voto é a arma do cidadão.

Temos assim que a associação entre alfabetização e participação presente nas lições de "Chave de Leitura" demonstra, ou melhor, explicita o propósito central da UP em relação ao investimento na educação dos adultos.

\section{CONSIDERAÇÕES FINAIS}

A experiência da UP sugere que Paschoal Lemme foi um educador e intelectual de expressão junto ao PCB. Particularmente no tocante aos problemas da educação de adultos, Lemme teve no partido o apoio necessário à divulgação das suas ideias e propostas, bem como para a materialização do seu pensamento.

Além de funcionar como espaço de sensibilização e recrutamento de trabalhadores para os sindicatos com vistas à sua qualificação para a participação política, tal como a educação de adultos organizada e dirigida por Lemme no âmbito do poder público local do Distrito Federal nos anos de 1930, a UP continha uma perspectiva alargada e continuada do processo de aprendizagem. Nesse sentido, era preciso considerar uma disposição dos tempos e espaços educativos que facilitasse a adesão e a frequência do trabalhador às atividades. Daí que a educação de adultos na UP foi estruturada de modo a oferecer simultaneamente "cursos elementares", "cursos de continuação, aperfeiçoamento e oportunidade" com base na flexibilidade em função dos interesses de grupos de alunos, sem formalidades especiais de matrícula, sem seriação rígida de matérias, sem horário fixo e com duração variável, segundo as necessidades e situações a que tinham de atender. Por sua vez, a presença dos "cursos de extensão cultural" na constituição da proposta conferia um papel pedagógico-político às artes e aos meios de comunicação na formação dos adultos.

Assim como o trabalho realizado nos cursos de continuação e aperfeiçoamento da Diretora de Educação de Adultos e Difusão Cultural do Distrito Federal foi interrompido na década de 1930, sob a suspeita de atuarem em favor da divulgação do marxismo, nos anos 1950 a UP foi fechada em função de denúncias que a julgavam um núcleo de atividades comunistas. A despeito das semelhanças entre as duas experiências, talvez a UP tenha sido o modelo educativo que melhor traduziu o modo de organizar a educação de adultos para que exercesse a função de atuar no processo de democratização da sociedade devido à longevidade que alcançou e à autonomia de que dispunha em relação ao Estado. 
Por certo, Paschoal Lemme não foi o único, dentre os educadores daquela época, a se envolver com o comunismo. Tampouco se dedicou exclusivamente ao problema da educação de adultos. Mas, nas mais diferentes ocasiões em que se pronunciou sobre o tema, ele atribuiu um lugar de destacada relevância à educação de adultos no processo de democratização da sociedade. Assim como na UP, a militância de Lemme em prol da educação de adultos baseou-se na articulação entre educação, participação política e melhoria das condições econômicas dos pobres. Nesse sentido, ao longo da sua trajetória como educador e intelectual, Lemme também ofereceu importantes contribuições para a escrita da história da educação dos trabalhadores no Brasil.

\section{REFERÊNCIAS}

Abreu, A. A. de. Revolta comunista de 1935. In: Abreu, A. A. de; Beloch, I.; Lattman-Weltman, F.; Lamarão, S. T. N. Dicionário Histórico-biográfico brasileiro pós-1930. Rio de Janeiro: Editora FGV; CPDOC, 2001.v. V.

Авu-Merhy, N. F. Cartilha para operário adulto - bases para sua organização. Rio de Janeiro: Ministério da Educação e Saúde, 1945.

Almeida, A. W. B. de. As bibliotecas marxistas e as escolas de partido. Religião e Sociedade. Rio de Janeiro. n. 9, jun. 1983.

A Manhã. Rio de Janeiro, p. 02, 21 nov. 1946.

Araújo, M. X. de. Chave da leitura (para adultos). Acervo da Fundação Biblioteca Nacional - Rio de Janeiro/Brasil, 1946. Indicação do Catálogo: II- 242, 2, 30.

Arquivos da Polícia Política. Comunismo. Relatório da Polícia Política, 1937. Pastas: 1785,1321, 1573. Disponível em: <http://www.siaapm.cultura.mg.gov.br >. Acesso em: 23 out. 2013.

Beisiegel. C. R. Estado e educação popular - um estudo sobre a educação de adultos. Brasília: Liber Livro, 2004.

Cunha, L. A. R. Educação e classes sociais no manifesto de 32: perguntas sem respostas. Revista da Faculdade de Educação, São Paulo, v. 20, n. 1-2, p. 132-150, 1994.

Diário de Notícias. Rio de Janeiro, p. 04, 11 jul. 1945.

. Rio de Janeiro, p. 08, 14 abr. 1946.

Elias, N. A sociedade de Corte: investigação sobre a sociologia da realeza e da aristocracia de corte. Rio de Janeiro: Zahar, 2001.

Gomes, Â. C. A invenção do trabalbismo. Rio de Janeiro: Editora FGV, 2005.

Imprensa Popular. Rio de Janeiro, p. 04, 20 abr. 1952.

Jornal do Brasil. Rio de Janeiro, p. 07, 02 mar. 1957.

Lemme, P. Educação de adultos. Conferência realizada a convite no Centro dos Professores das escolas noturnas municipais do Distrito Federal. Agosto de 1937a. (Arquivo Paschoal Lemme - PROEDES/UFRJ-RJ). 
Lemme, P. A educação de adultos no estado do Rio de Janeiro. Ante-projeto da organização da educação de adultos no estado do Rio de Janeiro, 1937b. (Arquivo digital Paschoal Lemme. Disponível em: <http://www.paschoallemme.com.br>. Acesso em: 28 out. 2014).

. Estudos de Educação. Rio de Janeiro: Livraria Tupã Ltda., 1953.

. Memórias de um educador - Paschoal Lemme. v. 4. Brasília: INEP, 2004.

. Educação de adultos - uma experiência de cursos de continuação, aperfeiçoamento e oportunidade realizada no Distrito Federal. Tese apresentada no concurso para técnico em educação do Ministério da Educação e Saúde, 1938.

МоттA, R. P. S. Em guarda contra o perigo vermelho: o anticomunismo no Brasil (19171964). São Paulo: Perspectiva: FAPESP, 2002.

Paiva, V. História da Educação Popular no Brasil - Educação popular e Educação de Adultos. São Paulo: Edições Loyola, 2003.

Pinheiro, M. C. O. Dos Comitês Populares Democráticos (1945-1947) aos movimentos de educação e cultura popular (1958-1964): uma história comparada. 2014. Tese (Doutorado em História) - Universidade Federal do Rio de Janeiro, Rio de Janeiro, 2014.

Priore, M. Do outro lado: a história do sobrenatural e do espiritismo. São Paulo: Planeta, 2014.

Saviani, D. Paschoal Lemme no manifesto: um estranho no ninho dos Pioneiros? Escola e democracia. Campinas: Autores Associados, 2008. (Coleção educação contemporânea). Sirinelli, J. F. Os intelectuais. In: Rémond, R. (Org.) Por uma história política. Rio de Janeiro: Editora FGV, 2003. p. 231-262.

Tribuna Popular. Rio de Janeiro, p. 03, 02 fev. 1946.

. Rio de Janeiro, p. 06, 24 mar. 1946.

. Rio de Janeiro, p. 03, 31 mar. 1946.

. Rio de Janeiro, p. 03, 02 jun. 1946.

. Rio de Janeiro, p. 03, 11 mar. 1947.

\section{SOBRE A AUTORA}

Cristiane Fernanda Xavier é doutora em educação pela Universidade Federal de Minas Gerais (UFMG). Professora da Universidade Federal de Alfenas (UNIFAL).

E-mail: cristianefx@yahoo.com.br

Recebido em 7 de dezembro de 2016

Aprovado em 21 de julho de 2017 